\title{
THE USE OF ANALYTICAL TECHNIQUES TO DETECT TOXIC SYNTHETIC DRUG, SIBUTRAMINE, ADULTERATED IN TRADITIONAL HERBAL MEDICINES
}

\author{
Zeenath Ismail Gadit, Mathi Kandiah
}

\begin{abstract}
Traditional herbal medicines (THM's) are still being used worldwide in at least $80 \%$ of the population, mainly in developing countries, due to the assumption that they are safer and cheaper. However, these medicines are now being adulterated with synthetic drugs causing toxic effects. One such drug is Sibutramine, a drug used for weight loss. Although Sibutramine has several promising weight loss effects, it causes several toxic side effects; this resulted in its banning and withdrawal from the market. Despite this, it is still being adulterated in herbal medicines and needs to be detected. It is detected using several analytical techniques such as TLC, GC, LC-MS, LCMS/MS, QTOF-LC/MS and more recently, spectroscopic techniques. Out of all the techniques, QTOF-LC/MS detected concentrations of Sibutramine adulterated in $9.4 \mathrm{mg}$ (not clear what this means) and had LOD and LOQ values of $0.4-2.0 \mu \mathrm{g} \mathrm{kg}-1$ and $1.3-6.0 \mu \mathrm{g} \mathrm{kg}-1$ respectively; therefore, QTOF-LC/MS is the best technique developed up to date when compared to all the other techniques. However, research is currently ongoing to combine spectroscopic techniques other than MS, to overcome disadvantages such as lack of global information, false-positive results, time and labor consumption to detect Sibutramine adulteration in the future.
\end{abstract}

Keywords: Toxic, Sibutramine, Adulteration, Analytical Techniques

\section{Introduction}

Traditional herbal medicines (THMs) are medicines made solely of a natural origin; they are rapidly gaining popularity all over the world as they are considered safer and cheaper alternatives to synthetic pharmaceuticals, and have no side effects (Haneef et al., 2013). The World Health Organization estimates at least $80 \%$ of the population that live in developing countries depend only on THM's (Skalicka-Wozniak, Georgiev, and Orhan, 2016). However, recently, it has been detected that these herbal medicines are adulterated with synthetics drugs that are not declared in the labels; the term adulteration refers to addition of substances that are not part of the actual mixture, or removal of an important component, which may present a risk of illness to the consumer (Miller et al., 2001). Adulteration is intentionally performed if the natural substances are expensive, short in supply or to increase pharmacologic efficacy (Haneef et al., 2013).

It was estimated in 2012 that about $69 \%$ of the adults in the United States were thought to be obese, which is an increase by $15 \%$ from 1970 (Creatore et al., 2016). This article focuses more on women, due to several cases of women being reported to take slimming drugs. Therefore, figure 1 illustrates the prevalence of obesity in women worldwide. 


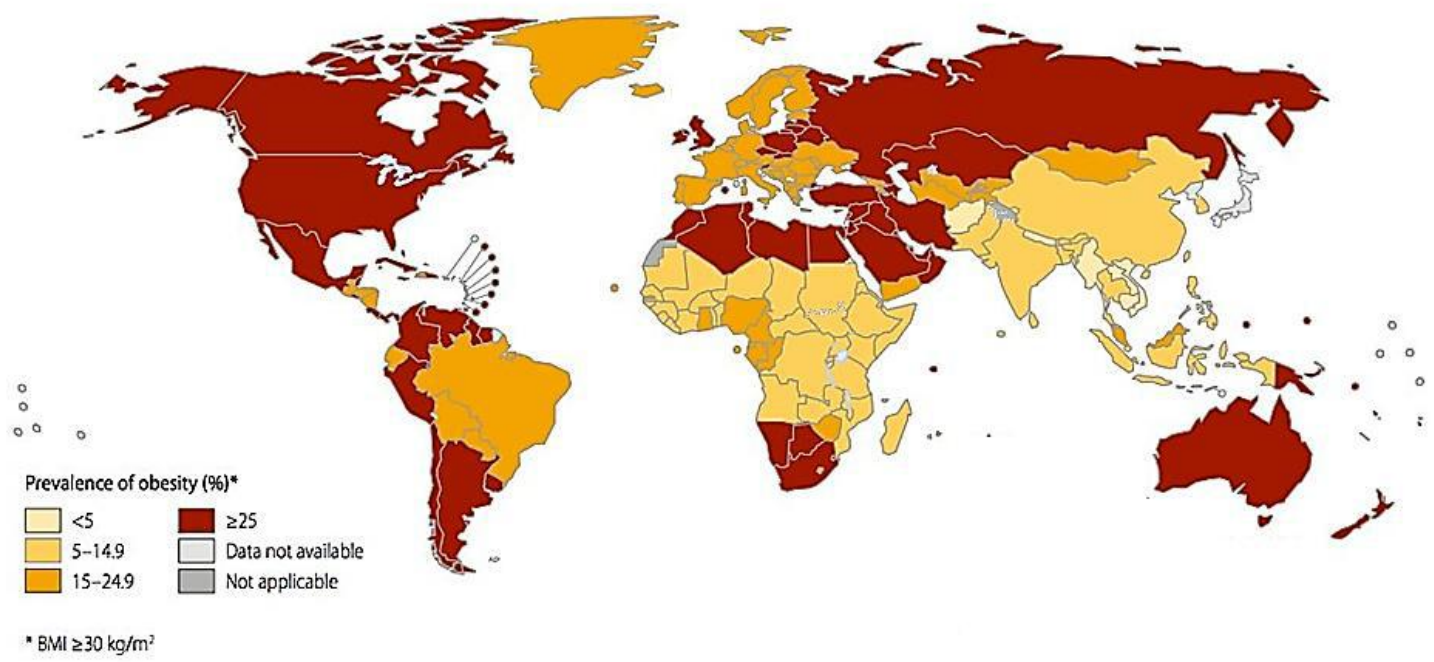

Figure 1: Prevalence of obesity in women older than 18 years in 2014 (Mendis, 2014)

A Food and Drug Administration (FDA) study in 2008 reported the adulteration of 72 herbal products, of which 94.4\% of them were adulterated with Sibutramine (Jordan, 2013). Sibutramine (N-\{1-[1-(4- chlorophenyl) cyclobutyl]-3-methylbutyl -N.N-dimethylamine) was first thought to be used as an antidepressant in the 1980's, but later it was found that it could be used as a drug to induce weight loss; it was therefore FDA approved and available for use in 40 countries since 1998 (Oberholzer et al., 2014; Florentin, Liberopoulos, and Elisaf, 2008). Sibutramine can be metabolized into its two analogues: N-mono-desmethylsibutramine and N-didesmethylsibutramine (Huang et al., 2008). The structures of sibutramine and its analogues are shown in Figure 2.

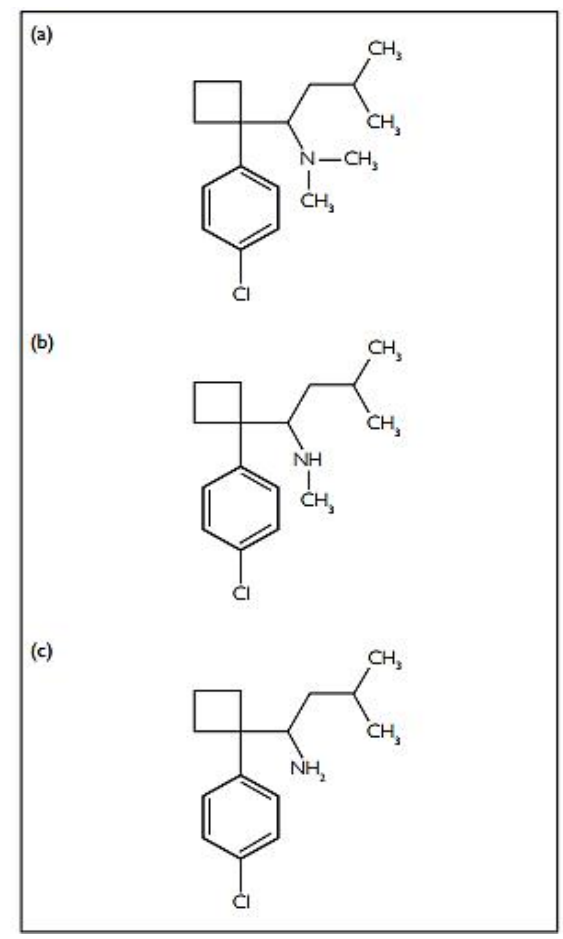

Figure 2: Chemical structures of (a) sibutramine, (b) N-desmethyl-sibutramine, and (c) N-bisdesmethylsibutramine (Yuen et al., 2007) 
Although sibutramine has promising results in weight loss, many side effects of the use of sibutramine have been observed such as headaches, insomnia, anorexia, dry mouth, confusion, dizziness, shivering, panic attacks, mood swings, hypertension, tachycardia and arrhythmias; therefore, in 2010, sibutramine was withdrawn and banned from markets due to its serious cardiovascular risks (Deconinck et al., 2014; Yu et al., 2010; Bogusz et al., 2006).

Despite this, sibutramine is still detected as an adulterant in THMs and therefore, it is essential to detect its presence. It is performed by using several analytical techniques that have developed throughout the years.

\section{Analytical techniques for the detection of Sibutramine}

Several analytical techniques have been developed for the detection of this adulteration. The techniques mentioned in detail in this review are thin layer chromatography (TLC), gas chromatography, liquid chromatography and spectroscopic techniques. These techniques have been improved over the years to overcome limitations such as sample handling, sample preparation, cost effectiveness, time taken, accuracy, sensitivity and precision.

\section{Thin layer chromatography (TLC)}

TLC is an older technique compared to other analytical techniques, but is still useful for the separation of compounds; in TLC a solid adsorbent phase is used such as a silica gel or alumina plate which first causes separation of the compounds (AlOthman and Rahman, 2013). The separated compounds are then carried up by a mobile phase and separated according to their respective retention times (Sjursnes, Kvittingen and Schmid, 2014).

In 2012, Phattanawasin and coworkers developed a simple TLC-image analysis method to detect sibutramine; chromatographic separation was performed using a silica gel $60 \mathrm{~F}_{254}$ TLC plate, toluene- $n$-hexane-diethylamine as the mobile phase and Dragendorff reagent for detection of spots (Figure 3). This was the first validated report for the method and detected amounts of sibutramine adulterated in herbal medicines ranging from 6- $24 \mathrm{mg}$. The limits of detection (LOD) value was obtained as $190 \mathrm{ng} / \mathrm{spot}$ and the limits of quantification (LOQ) was obtained at $634 \mathrm{ng} / \mathrm{spot}$ (Phattanawasin et al., 2012).

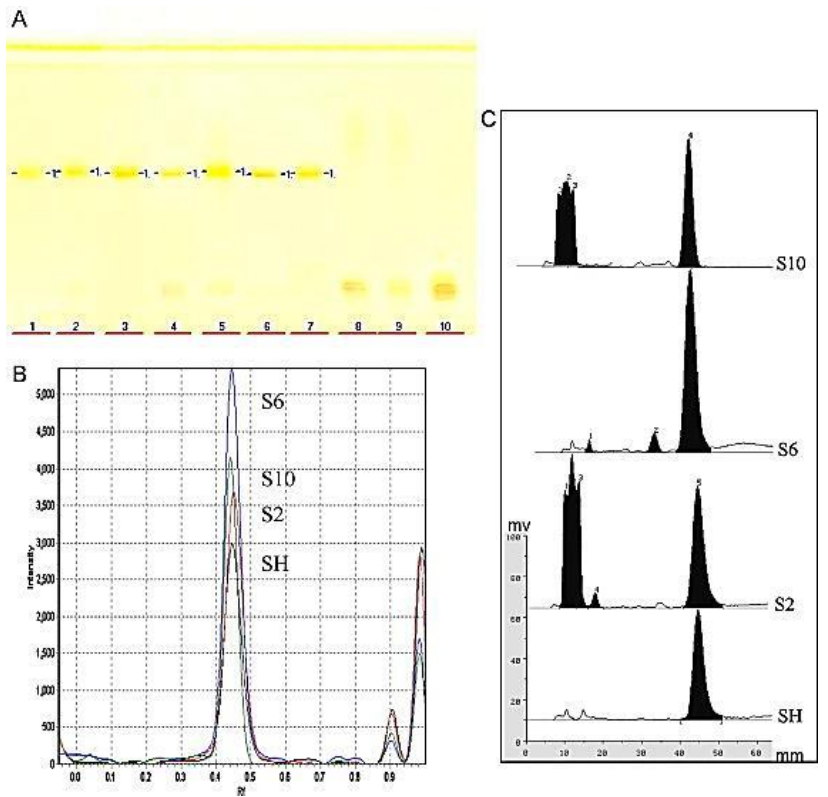

Figure 3: (A) TLC image of standard Sibutramine (track 1), adulterated slimming formulations (tracks 2-7: S2, S6, S7, S9, S10 and S19) and Sibutramine-free samples (tracks 8-10: S14, S15 and S16), (B) TLC 
chromatogram of standard Sibutramine, slimming coffee (S2), slimming gel (S6) and slimming capsule (S10) obtained from TLC-image analysis and (C) from TLC-densitometry (Phattanawasin et al., 2012).

High Performance TLC (HPTLC) is an improved form of TLC due to the addition of a number of features that end up automating steps, increasing resolution and also result in more accurate results (Raja, 2015). Therefore, in 2012, Ariburnu and coworkers performed an HPTLC-densitometry method using glass HPTLC plates coated with silica gel 60 F254 and a mobile phase of $n$-hexane-acetone-ammonia; the LOD and LOQ calculated were 77.34 and 257.79ng respectively (Ariburnu et al., 2012). Following this, in 2014, Mathon and coworkers performed an HPTLC-UV method using HPTLC silica gel plates and a mobile phase of toluene-methanol mixture; quantification and confirmation of sibutramine were then performed using TLC-MS; the results found half of 52 herbal samples adulterated with sibutramine, with concentrations up to 35mg (Mathon et al., 2014). However, HPTLC has limitations such as poor precision, which therefore render it less suitable for quantitative analysis (Haneef et al., 2013).

TLC is used because it is a simple, rapid method with a low cost of operation; however, its major disadvantages are that it has a low sensitivity and low precision (Rocha, Amaral, and Oliveira, 2015). In addition, tests involving only chromatography, such as TLC cannot be used to identify the compound; rather, they confirm the necessity to perform further tests such as spectrometry, for qualitative or quantitative analysis (Csupor et al., 2013). Therefore, hyphenated GC and LC techniques were developed and used more frequently than TLC.

\section{Gas chromatography-Mass spectrometry (GC-MS)}

GC-MS is a hyphenated technique that combines both GC and MS; GC separates components in the sample, and the fragments are then analyzed according to their mass using MS (Chauhan, Goyal and Chauhan, 2014).

In February 2006, a metabolite of sibutramine was detected and identified in the urine of a 16 year old girl (Figure 4) who was admitted to the hospital due to side effects observed by the consumption of the Chinese herbal drug "LiDa Dai Dai Hua Jiao Nang"; identification was performed using a GC-MS system composed of an Agilent 6890 gas chromatograph with an Agilent 5973 mass selective detector and an Ultra 1 column (Vidal and Quandte, 2006). However, no quantification was performed in this method.

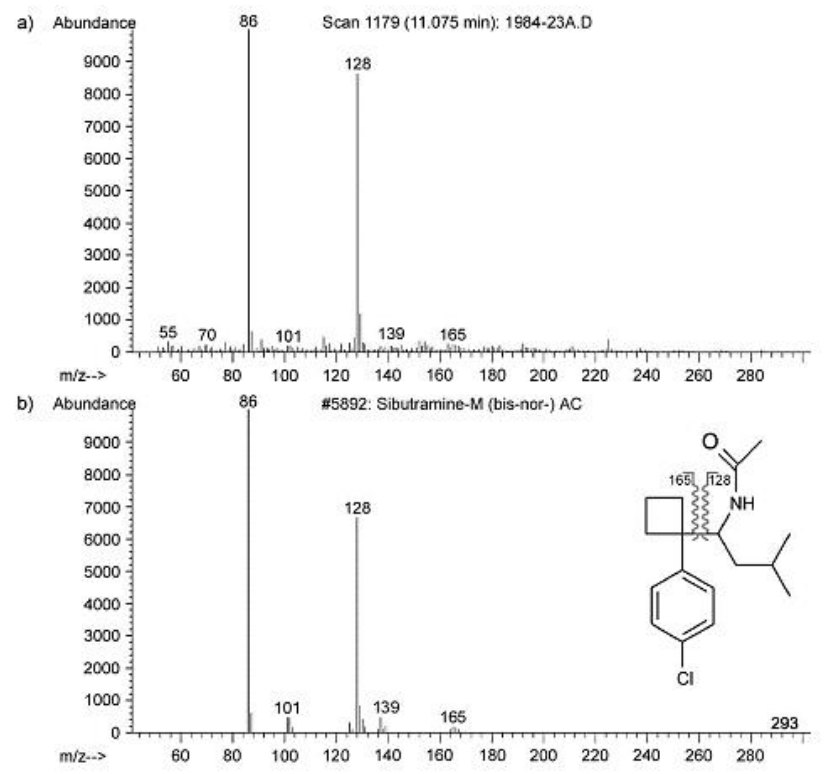

Figure 4: Acetylated derivative (a) of the bis-demethylated Sibutramine-metabolite $\left(\mathrm{Mr}=293,84 ; \mathrm{C}_{17} \mathrm{H}_{24} \mathrm{ClNO}\right)$ and reference spectrum (b) selected from spectra library (Vidal and Quandte, 2006) 
Furthermore, an additional case was reported in 2012 and an Agilent model 6890 GC and 5973 mass selective detector and a DB-17MS GC-MS method was used (Figure 5); the test showed that each capsule contained 22 mg of sibutramine (Da lio lu and Akcan, 2012).
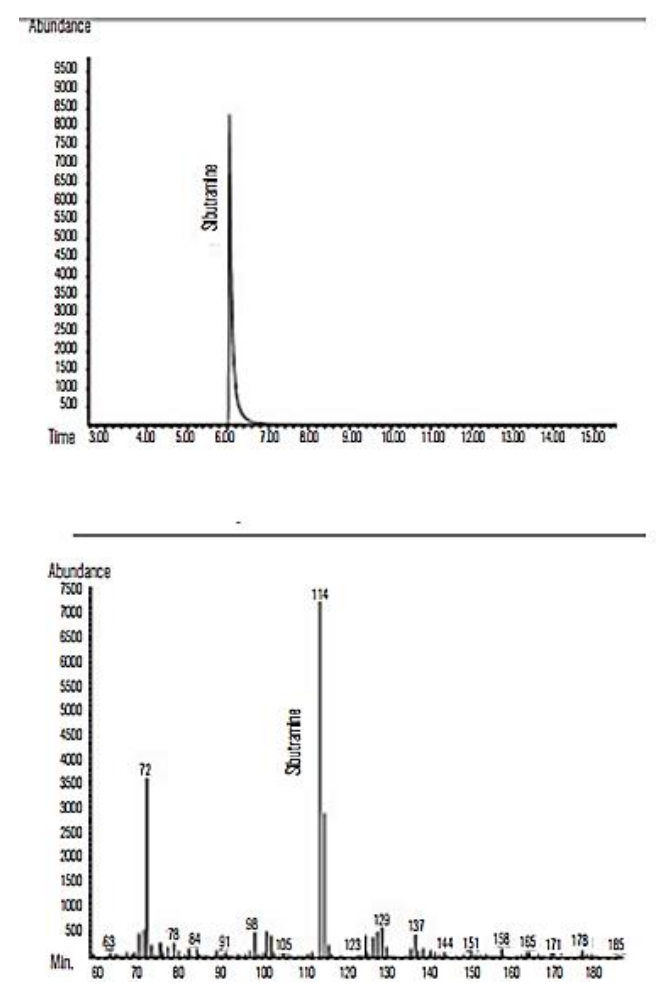

Figure 5: GC-MS chromatogram of sibutramine in herbal drug (LiDa) capsule - the total ion chromatogram (Da lio lu and Akcan, 2012)

A study conducted in 2014 used GC/MS (Agilent 7000, Triple Quaed, GC7890A) with a capillary column for the stationary phase; linear calibration range was between $1-500 \mu \mathrm{g} / \mathrm{mL}$ and the LOQ was $5 \mathrm{ng} / \mathrm{mL}$. Sibutramine was detected in amounts ranging from 6-78 mg/capsule (Khazan et al., 2014).

The main advantage of GC-MS is the fact that it can analyze volatile compounds and has a high sensitivity; conversely, the biggest disadvantage of GC-MS is that it cannot detect polar and non-volatile compounds; therefore, LC methods are preferred over GC (Kamboj, 2012).

\section{Liquid Chromatography (LC)}

Prior to the ionization and mass analysis of molecules, LC plays an important role in separation of a bulk sample matrix (which could later cause interference or suppression of the signals of the compound actually being detected); furthermore, if a standard is available, LC can identify the compound based on the retention time (Vaclavik, Kryntisky and Rader, 2014). However, LC is not usually used alone to detect the presence of Sibutramine in THM's. It can be developed and used as High Performance Liquid Chromatography (HPLC), or more commonly hyphenated with MS to give rise to techniques such as LC-MS, LC-MS/MS (tandem mass spectrometry) and Quadrupole time of flight (QTOF) - LC/MS. 


\section{HPLC}

A case was reported in September 2006, of a 20 year old woman who had seen her family doctor after the use of the same drug "LiDa" mentioned earlier, and experiencing side effects; detection was performed using GC-MS with an Optima-1-MS capillary column and was followed up by an HPLC-DAD method for quantification of the drug; the quantification yielded $27.4 \mathrm{mg}$ of sibutramine adulterated in the drug, which is approximately twice the accepted prescribed amount (Jung, Hermanns-Clausen and Weinmann, 2006).

A further study was developed in 2011; Sibutramine was detected in the quantity of 30mg per capsule and one of its metabolites, N, N-didesmethylsibutramine was also detected. LOQ's varied from 0.1-5.0 $\mu \mathrm{g} / \mathrm{ml}$. However, the procedure was validated by an unconventional method, as it did not investigate the precision or accuracy of the method (Ancuceanu, Dinu and Arama, 2013; Rebiere et al., 2011).

Therefore, a validated HPLC method was developed in 2013 (Figure 6b). 24.71mg (97.28 mg g-1) of Sibutramine was detected; the LOQ values ranged from 4.47-7.81 $\mu \mathrm{g} / \mathrm{mL}$ and the LOD ranged from 1.34-2.34 $\mu \mathrm{g} / \mathrm{mL}$ (Ancuceanu, Dinu and Arama, 2013).
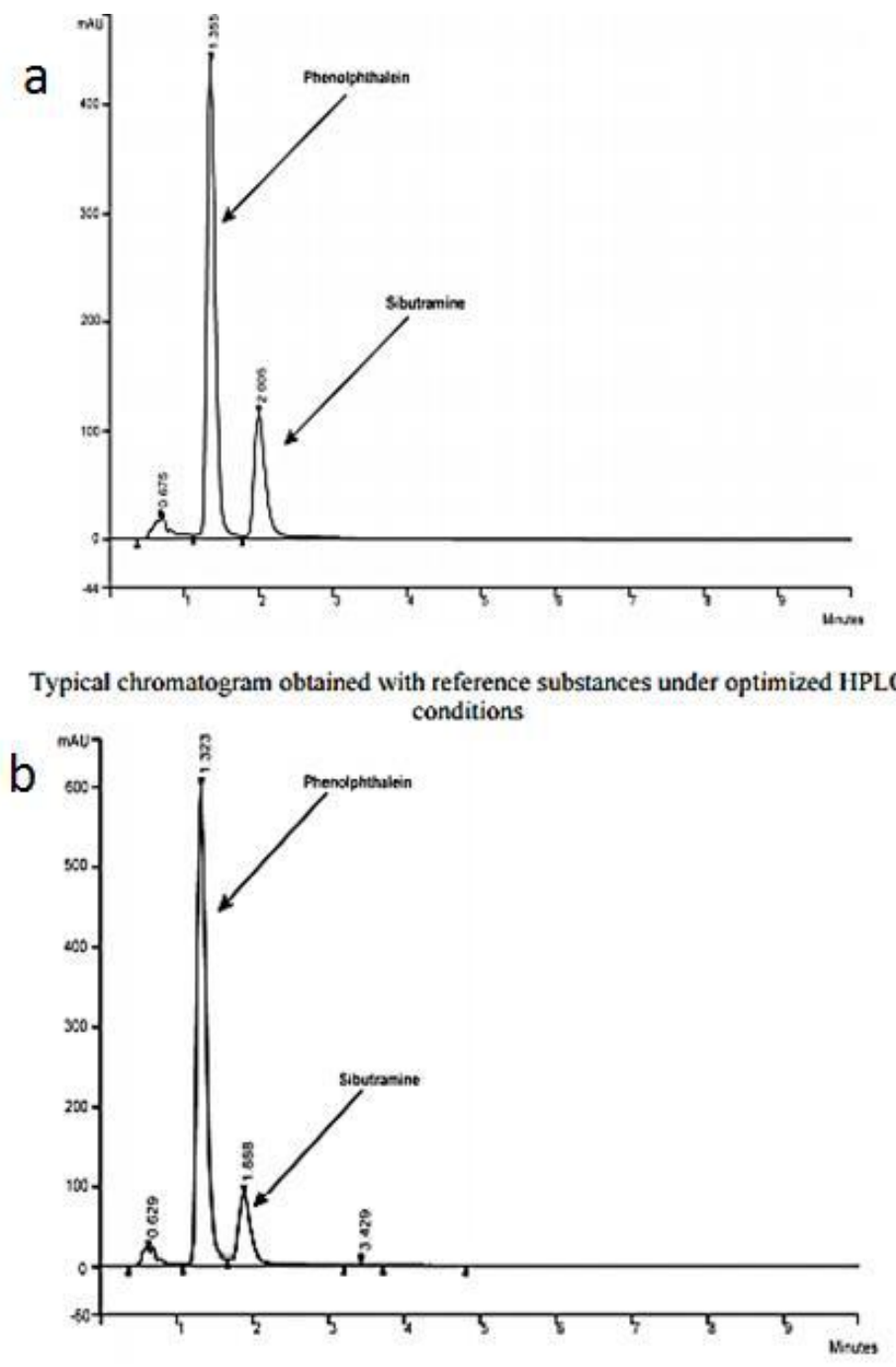

Figure 6: (a) Typical chromatogram obtained with reference substances under optimized HPLC conditions and (b) the chromatogram obtained with capsule content of an adulterated for the herbal supplement (CS) (Ancuceanu, Dinu and Arama, 2013) 
The different equipment used and results obtained are summarized below in table 1 .

Table 1: The equipment used for the HPLC techniques and their respective LOD and LOQ values

\begin{tabular}{|c|c|c|c|c|c|}
\hline Equipment & Solvent & LOD & LOQ & $\begin{array}{l}\text { Sibutramine } \\
\text { concentration } \\
\text { detected (mg) }\end{array}$ & Reference \\
\hline $\begin{array}{l}\text { LiChrospher } 100 \AA \\
\text { RP-8 column }\end{array}$ & - & - & - & 27.4 & $\begin{array}{l}\text { Jung, Hermanns- } \\
\text { Clausen and } \\
\text { Weinmann, } 2006\end{array}$ \\
\hline $\begin{array}{l}\text { A trifunctional C18 } \\
\text { end capped column } \\
\text { and a photodiode } \\
\text { array detector }\end{array}$ & $\begin{array}{l}\text { Phosphate } \\
\text { buffer } \\
\text { acetonitrile }\end{array}$ & - & $\begin{array}{l}0.1-5.0 \\
\mu \mathrm{g} / \mathrm{ml}\end{array}$ & 30 & Rebiere et al., 2011 \\
\hline \begin{tabular}{lr}
\multicolumn{2}{l}{ Varian HPLC } \\
+ Pystem \\
+ quaternary & $240 S D M$ \\
puagh- \\
pressure & pump, \\
diode-array & detector \\
$+\quad \mathrm{CN}$ & Nucleosil \\
column &
\end{tabular} & $\begin{array}{l}\text { Phosphate } \\
\text { buffer and } \\
\text { acetonitrile }\end{array}$ & $\begin{array}{l}1.34-2.34 \\
\mu \mathrm{g} / \mathrm{mL}\end{array}$ & $\begin{array}{l}4.47-7.81 \\
\mu \mathrm{g} / \mathrm{mL}\end{array}$ & 24.71 & $\begin{array}{l}\text { Ancuceanu, Dinu } \\
\text { and Arama, } 2013\end{array}$ \\
\hline
\end{tabular}

Due to the ability of LC systems to withstand high pressures has become more available, UPLC/MS methods are being developed; advantages of UPLC over HPLC include decreased run time, reduced solvent consumption, improved peak capacity and sensitivity, which allows multi-analyte screening (Nielsen et al., 2010).

\section{LC-MS}

By the use of only HPLC, sibutramine was able to be detected as an adulterant; however, by the use of only HPLC, less precise results tend to be obtained. To overcome this, mass spectrometry is hyphenated with techniques such as LC to give higher precision and accuracy. LC-MS is used as a tool for detection of undeclared synthetic adulterants in THM's due to its application in detecting a wide range of compounds; in addition, it provides both quantitative and structural data of the analytes. It can also be paired with different ionization techniques such as electrospray ionization (ESI), fast atom bombardment (FAB) and direct analysis in real time (DART), depending on the analyte being detected (Haneef et al., 2013). It is also paired with different mass analyzers such as triple quadrupole (QqQ), single quadrupole (Q), ion trap (IT) and time-of-flight (TOF); furthermore, hybrid systems such as quadrupole-time-of-flight (QqTOF) have also been developed (Vaclavik, Kryntisky and Rader, 2014).

A further method of analysis is liquid chromatography tandem mass spectrometry (LC-MS/MS), in which a further mass spectrometric analysis is performed to confirm the compound detected. This is one of the most commonly used techniques for the detection of adulteration of THM's; it is used due to its specificity, selectivity, sensitivity, less sample preparation and because it provides quantitative results (Haneef et al., 2013). 
In 2005, an LC-MS-MS method was developed that was successful in detecting synthetic drugs in herbal medicines, but was not used to detect Sibutramine (Liang et al., 2006). In 2006, Bogusz and coworkers performed an LC-ESI-MS-MS technique by the use of a TSQ quantum LC/MS/MS together with a Surveyor AS Autosampler and quaternary LC pump; this method that detected 20 weight reducing adulterants in THM's; however, Sibutramine was not detected using this method as well (Bogusz et al., 2006).

Therefore, a specific and accurate HPLC-ESI-MS method was developed in 2008 by Wang and coworkers, that targeted the detection of Sibutramine and its metabolites; separation by chromatography was done using a $\mathrm{C}_{8}$ reversed-phase column and solvents of acetonitrile and ammonium formate were used (Figure 7). The LOD ranged from $0.0018-0.73 \mu \mathrm{g} \mathrm{g}^{-1}$; three of the six samples analyzed were found to contain either Sibutramine or $\mathrm{N}$-mono-desmethylsibutramine at levels of 0.212- $96.2 \mathrm{mg} \mathrm{g}^{-1}$ (Wang, Chen and Yao, 2008).
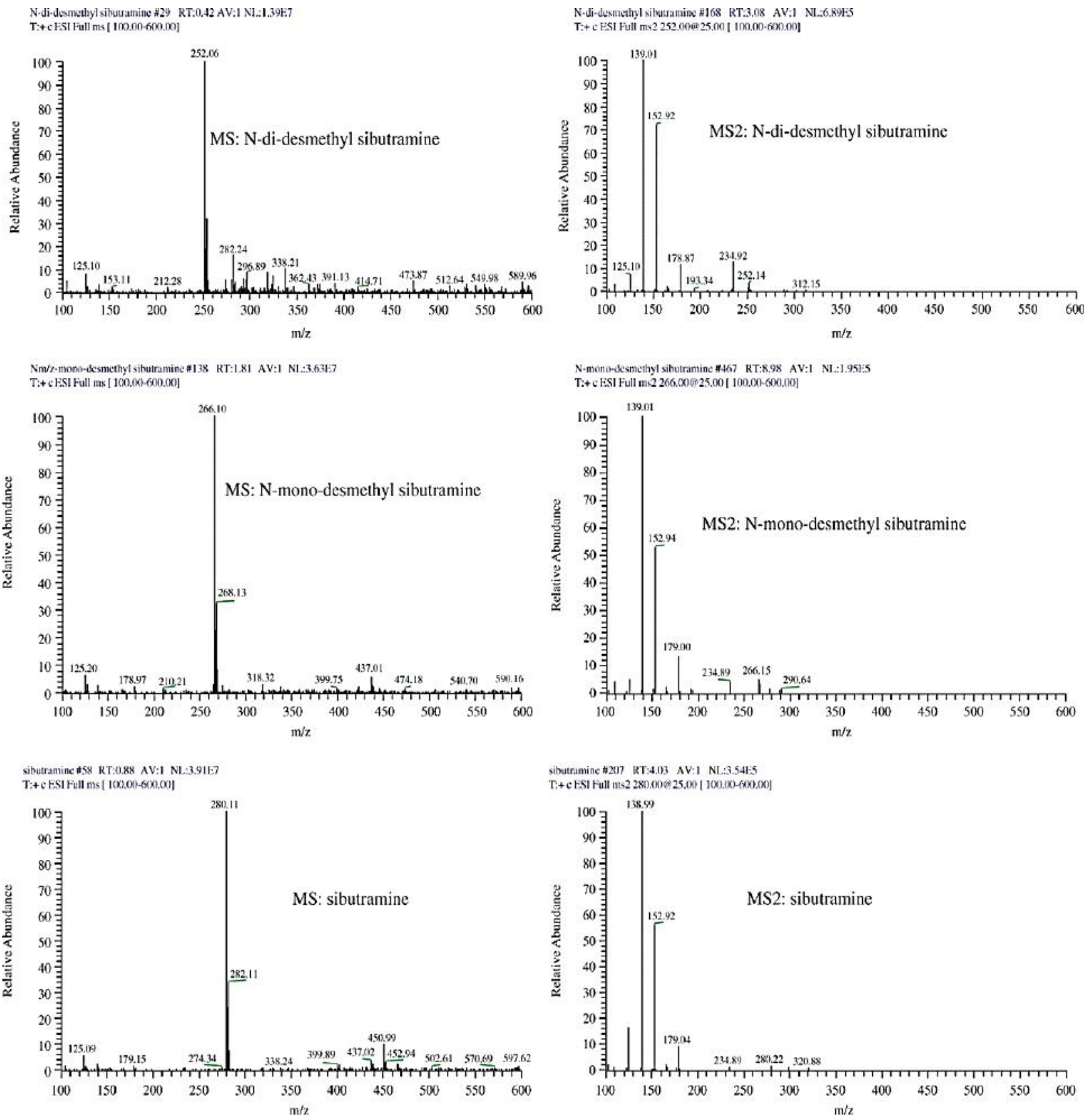

Figure 7: $\mathrm{MS}^{2}$ spectrum of N-di-desmethyl sibutramine, N-mono-desmethyl sibutramine, sibutramine. The mass spectrometer used was a Finnigan LCQ Advantage MAX (Thermo, USA). ESI+; sheath gas flow rate: 40 arb; 
aux/sweep gas flow rate: $5 \mathrm{rab}$; spray voltage: $3 \mathrm{kV}$; capillary temperature: $260^{\circ} \mathrm{C}$; capillary voltage: $30 \mathrm{~V}$; tube lens offset: $30 \mathrm{~V}$; collision energy: 25\%. (Wang, Chen and Yao, 2008)

Furthermore, an HPLC-ESI-MS/MS method was established by Shi and coworkers in 2011, using a Hypersil Gold column and solvents of formic acid-ammonium formate buffer and methanol; Sibutramine was detected and the LOD was $0.03 \mathrm{mg} / \mathrm{kg}$ and the LOQ value was $0.10 \mathrm{mg} / \mathrm{kg}$, with a mean recovery of $89.9 \%$ (Shi et al., 2011).

A newer method of LC-MS-MS through MRM and EPI mode, plus library searching method was developed in 2009 by Chen and coworkers, which successfully detected Sibutramine in 8 botanical dietary supplements; the LOD value was found to be satisfactory to screen for adulterants. The method used 3200 QTRAP Hybrid Quadrupole-Linear Ion Trap Mass (Chen et al., 2009). In 2013, an LC-ESI-MS/MS method was developed using a reverse phase column and solvents of acetonitrile and water with $0.1 \%$ formic acid; analysis was then performed using multiple reaction monitoring (MRM) ratios. Sibutramine was detected in concentrations of $0.000184-4.81 \mathrm{mg} /$ capsule, the LOD was $1.3 \mathrm{ng} / \mathrm{ml}$ and the LOQ was $4.0 \mathrm{ng} / \mathrm{ml}$. This method was accurate, easy to perform, precise and sensitive (Yano et al., 2013).

\subsubsection{Quadrupole Time of Flight Liquid Chromatography Mass spectrometry (QTOF LC/MS)}

The QTOF analyzer functions by acceleration of ions through a tube by the use of a high voltage; molecules are then detected, and the time taken to reach the detector depends on the compound's respective $\mathrm{m} / \mathrm{z}$ values. It is a newer technique and is starting to be used more often because of its advantages such as high resolving power, high mass accuracy, and high sensitivity (Pitt, 2009).

In 2007, Zou and coworkers were the first to report detection of two active metabolites along with a new analogue of Sibutramine in a THM, by the employment of TOF-LC/MS. $1 \mathrm{~g}$ of the samples were required and equipment used were an Agilent 1200 series LC system coupled with an Agilent 6210 TOF mass spectrometer; TOF-LC/MS determined and thereby suggested molecular formulae of $\mathrm{C}_{15} \mathrm{H}_{22} \mathrm{NCl}, \mathrm{C}_{16} \mathrm{H}_{24} \mathrm{NCl}$ and $\mathrm{C}_{17} \mathrm{H}_{26} \mathrm{NCl}$. Therefore, the two metabolites were confirmed as $\mathrm{N}$-didesmethylsibutramine and $\mathrm{N}$-desmethylsibutramine, whereas the analogue detected was termed Homosibutramine (Figure 8) (Zou et al., 2007). 

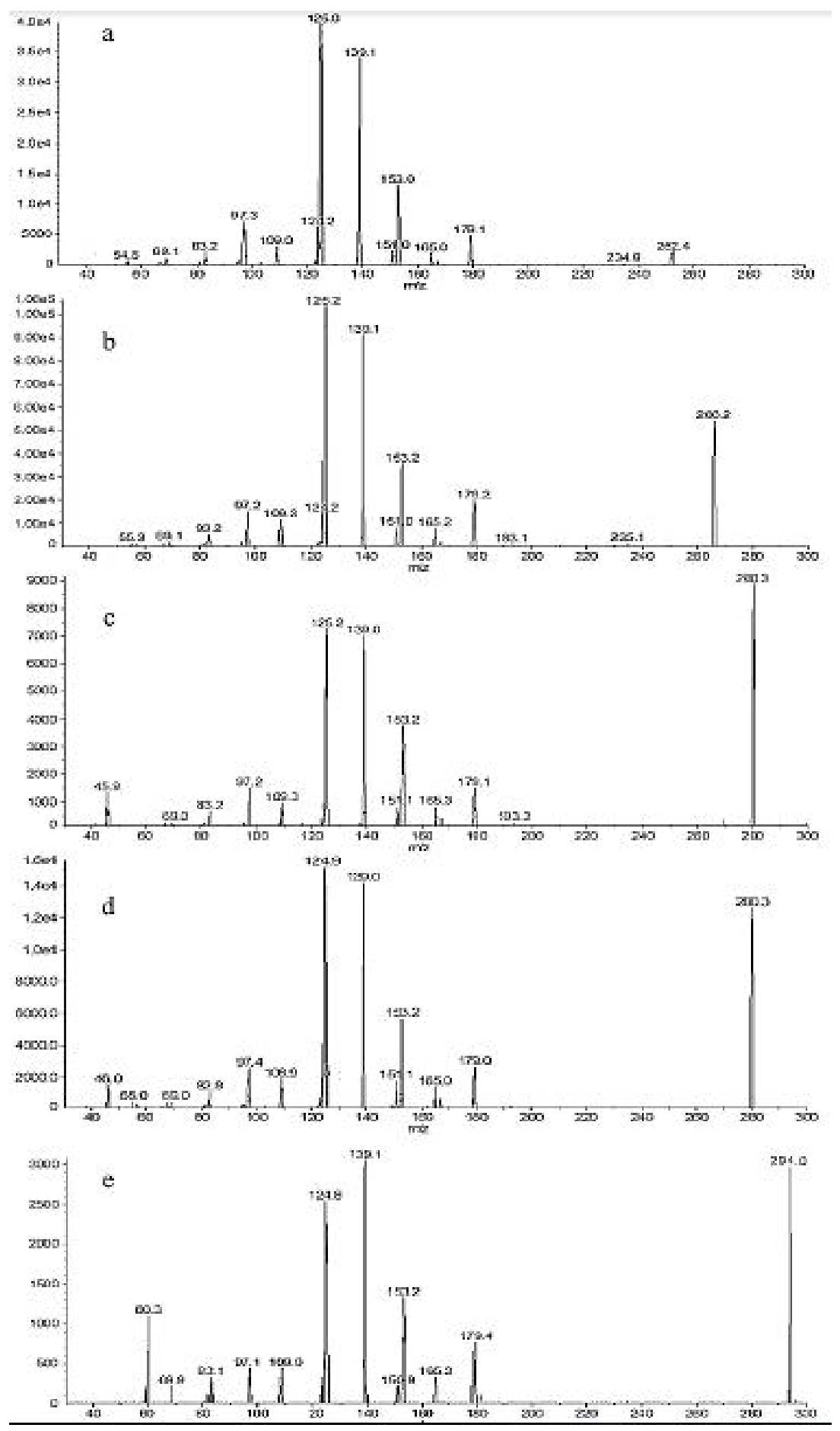

Figure 8: MS/MS product spectra of $[\mathrm{M}+\mathrm{H}]^{+}$ions of compunds (a) N-didesmethylsibutramine, (b) Ndesmethylsibutramine, (c) sibutramine, (d) isomer of sibutramine and (e) homosibutramine (Zou et al., 2007)

In 2011, a UPLC/Q-TOF MS (Figure 9) was implemented to detect Sibutramine and its 2 major metabolites; a waters ACQUITY UPLC system coupled to a Bruker micrOTOF-q II mass spectrometer with a waters ACQUITY chromatographic column was used; solvents used were formic acid, acetonitrile. UPLC was used here due to its short analysis time and good repeatability during analysis. The test detected sibutramine and its analogues, specifically N-desmethylsibutramine (9.4 mg); the LOD and the LOQ were from $0.4-2.0 \mu \mathrm{g} \mathrm{kg}^{-1} \mathrm{and}^{-}$ from 1.3- $6.0 \mu \mathrm{g} \mathrm{kg}^{-1}$ respectively (Roh et al., 2011). UPLC/Q-TOF/MS is considered a powerful technique to detect components that are low in abundance in the drugs due to its features of high resolution, reproducibility and selectivity (Li et al., 2011). 


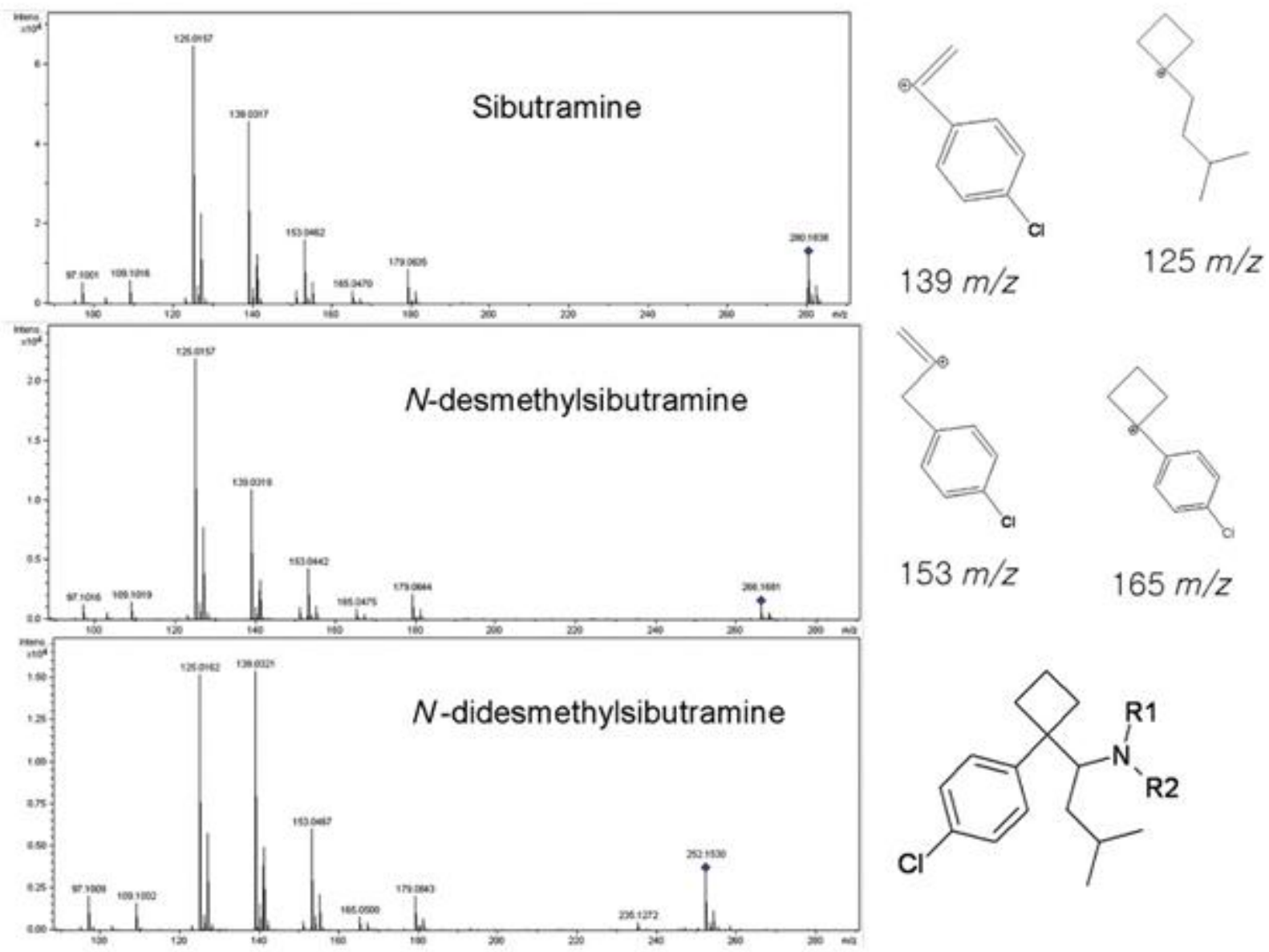

Figure 9: Mass fragmentation pattern and fragment compounds of the compound Sibutramine and its analogues. (Roh et al., 2011)

Methods involving LC coupled with various detectors (usually MS), have the advantage of high sensitivity; however, they also have disadvantages of being laborious, time consuming and the fact that they are too selective and cannot provide global information in detecting a particular component, because compositions of drugs vary among different brands (Monakhova et al., 2012). These methods were also considered to have inadequate reliability for screening because herbal medicines contain a complex mixture of many components which may interfere with chromatographic and mass spectroscopic assays (Calahan et al., 2016). Furthermore, chromatographic methods can yield false-positive results; therefore, these methods cannot be ideal for screening of adulterated drugs in THMs (Vaysse et al., 2010).

Therefore, recently, techniques related to coupling with spectroscopic techniques have been developed to analyze for Sibutramine adulteration.

\subsection{Spectroscopic methods}

The chromatographic methods can be coupled with spectroscopic techniques such as NMR spectroscopy, Fourier transform infrared (FTIR) spectroscopy with attenuated total reflectance (ATR), portable ion mobility spectrometer (IMS), Raman Spectroscopy and X-ray powder diffractometry, to analyze for Sibutramine adulteration (Nnaji et al., 2016). The use of chromatographic techniques paired with other detection methods is not the ideal method of detection because these techniques maybe too selective sometimes and not provide global information; furthermore, false-positive results may also occur (Vaysse et al., 2010). Moreover, to spare the time loss of using chromatographic methods, more spectroscopic-related techniques have been developed (Nnaji et al., 2016). 
One particular method developed was the use of an LC-QTOF-MS method combined with NMR spectroscopy, using the basic principle of generating a peak with the initial LC-QTOF-MS, where MS identifies the compound; the identity is then confirmed by using NMR and quantified using qNMR. This method detected Sibutramine along with other adulterants (Figure 10); the concentration of Sibutramine detected in the capsule LIPO8 was $1 \mathrm{mg}$. A measurement uncertainty of $1.5 \%$ was reported, with an $\mathrm{S} / \mathrm{N}$ ratio of 150:1 or more; these two values were then applied as the LOQ (Johansson et al., 2014).

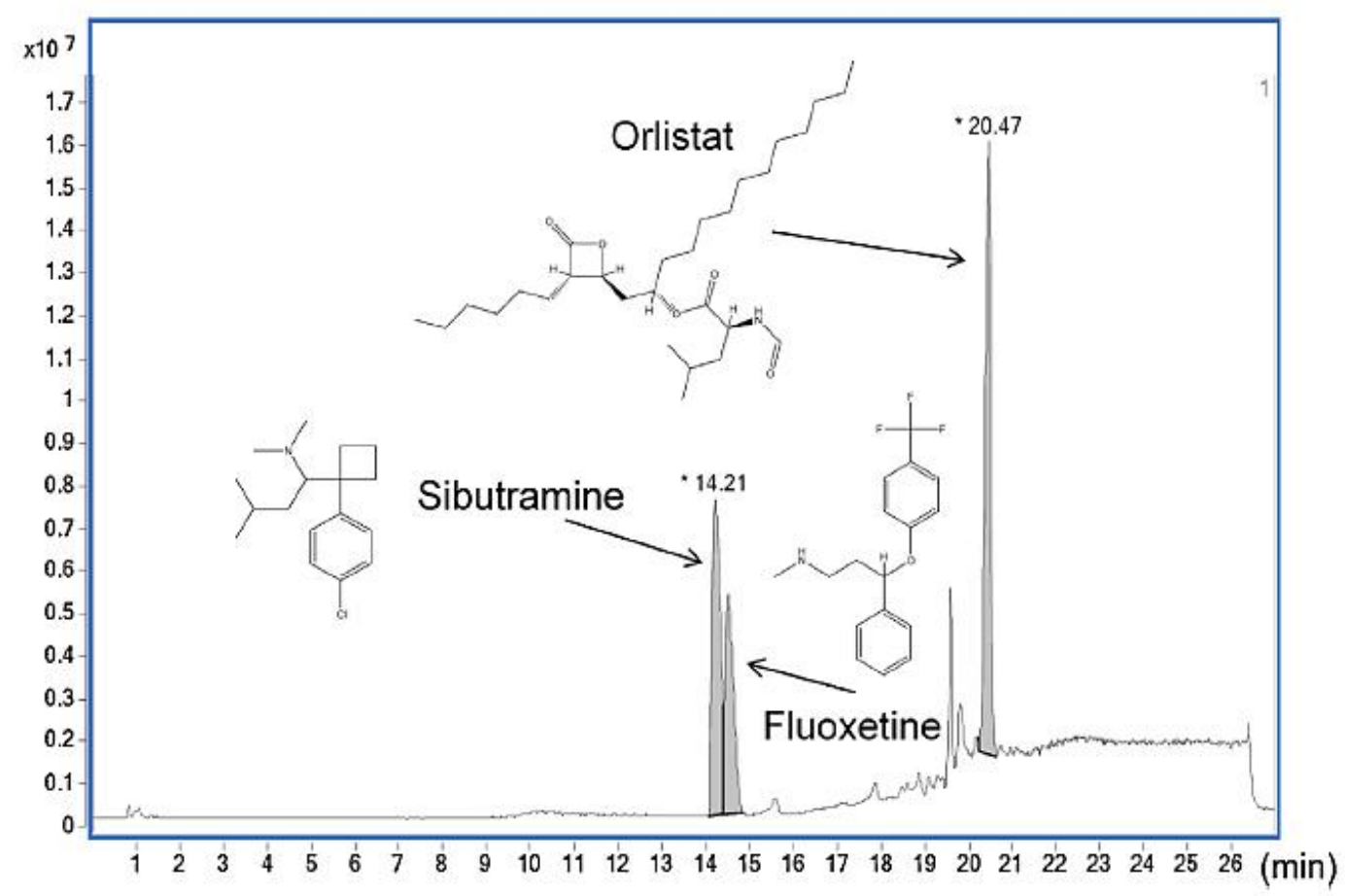

Figure 10: Chromatogram of LIPO8, a food supplement containing undeclared active pharmaceutical ingredients. Slimming product seized by Swedish customs. Sibutramine detected at $1 \mathrm{mg} / \mathrm{capsule}$. Detector: MS TOF; scan m/z 110-1000 scan rate 1s; centroid (Johansson et al., 2014)

\section{Future prospects}

To detect chemical compounds adulterated in a herbal sample by spectroscopy, the compound must be present in large doses with no masking effects from the other components in the sample; else, the spectroscopic result alone is not reliable; therefore, it is best to combine the spectroscopic techniques with separation techniques (Deconinck et al., 2013; Lu et al., 2007). Therefore, research is still being performed in combining more spectroscopic techniques other than MS with liquid chromatography methods, to work and develop spectroscopic techniques that overcome these disadvantages and use them to detect the adulteration of Sibutramine in THM's.

\section{Summary}

Table 2 summarizes the main techniques described in this review.

Table 2: Summary of the techniques including TLC, GC-MS, HPLC, LC/MS/MS and QTOF-LC/MS 


\begin{tabular}{|c|c|c|c|c|c|}
\hline Method & Equipment & LOD & LOQ & $\begin{array}{l}\text { Sibutramine } \\
\text { concentration } \\
\text { detected }\end{array}$ & Reference \\
\hline $\begin{array}{l}\text { TLC-image } \\
\text { analysis }\end{array}$ & $\begin{array}{l}\text { Silica gel } 60 \mathrm{~F}_{254} \mathrm{TLC} \\
\text { plate, toluene- } n \text {-hexane- } \\
\text { diethylamine } \quad(9: 1: 0.3 \text {, } \\
\mathrm{v} / \mathrm{v} / \mathrm{v})+ \text { Dragendorff } \\
\text { reagent }\end{array}$ & $\begin{array}{l}190 \mathrm{ng} / \mathrm{sp} \\
\text { ot }\end{array}$ & $634 \mathrm{ng} / \mathrm{spot}$ & 6- $24 \mathrm{mg}$ & $\begin{array}{l}\text { Phattanawasi } \\
\text { n et al., } 2012\end{array}$ \\
\hline GC/MS & $\begin{array}{l}\text { Agilent } 7000, \text { Triple } \\
\text { Quaed, GC7890A) + } \\
\text { capillary column }\end{array}$ & - & $5 \mathrm{ng} / \mathrm{mL}$ & 6-78 mg & $\begin{array}{l}\text { Khazan et al., } \\
2014\end{array}$ \\
\hline HPLC & $\begin{array}{l}\text { Varian HPLC system + } \\
\text { Prostar } 240 \text { SDM } \\
\text { quaternary } \\
\text { pressure pump, diode- } \\
\text { array detector }+ \text { CN } \\
\text { Nucleosil column }\end{array}$ & $\begin{array}{l}1.34-2.34 \\
\mu \mathrm{g} / \mathrm{mL}\end{array}$ & $\begin{array}{l}4.47-7.81 \\
\mu \mathrm{g} / \mathrm{mL}\end{array}$ & $24.71 \mathrm{mg}$ & $\begin{array}{l}\text { Ancuceanu, } \\
\text { Dinu and } \\
\text { Arama, } 2013\end{array}$ \\
\hline $\begin{array}{l}\text { LC-ESI- } \\
\text { MS/MS }\end{array}$ & $\begin{array}{l}\text { Reverse phase column } \\
+\quad \text { solvents of } \\
\text { acetonitrile and water } \\
\text { with } 0.1 \% \text { formic acid. } \\
\text { Analysis by multiple } \\
\text { reaction monitoring } \\
(\text { MRM) ratios }\end{array}$ & $1.3 \mathrm{ng} / \mathrm{ml}$ & $4.0 \mathrm{ng} / \mathrm{ml}$ & $\begin{array}{l}0.000184-4.81 \\
\mathrm{mg} / \text { capsule }\end{array}$ & $\begin{array}{l}\text { Yano et al., } \\
2013\end{array}$ \\
\hline QTOF-LC/MS & $\begin{array}{l}\text { Waters ACQUITY } \\
\text { UPLC system coupled } \\
\text { to a Bruker micrOTOF- } \\
\text { q II mass spectrometer } \\
+ \text { solvents of } 0.1 \% \\
\text { formic acid (A) and } \\
0.1 \% \text { formic acid in } \\
\text { acetonitrile (B) }\end{array}$ & $\begin{array}{l}0.4- \\
2.0 \mu \mathrm{g} \mathrm{kg} \\
-1\end{array}$ & $\begin{array}{l}1.3- \\
6.0 \mu \mathrm{g} \mathrm{kg}^{-1}\end{array}$ & $9.4 \mathrm{mg}$ & $\begin{array}{l}\text { Roh et al., } \\
2011\end{array}$ \\
\hline \multirow[t]{2}{*}{$\begin{array}{l}\text { LC-QTOF-MS } \\
+ \text { NMR }\end{array}$} & $\begin{array}{l}\text { LC-QTOF-MS } \\
\text { of } \quad 1290 \quad \text { Infinity } \\
\text { UHPLC }+ \text { diode array } \\
\text { detector + }\end{array}$ & - & $\begin{array}{l}\mathrm{S} / \mathrm{N} \text { ratio of } \\
150: 1\end{array}$ & $1 \mathrm{mg} /$ capsule & $\begin{array}{l}\text { Johansson et } \\
\text { al., } 2014\end{array}$ \\
\hline & $\begin{array}{l}\text { a reversed phase } \\
\text { column, Aqcuity UPLC }\end{array}$ & & & & \\
\hline
\end{tabular}


Bruker Avance

spectrometer

In summary, the detection of Sibutramine adulteration THM's is very important due to the side effects it possesses, and despite it being banned and withdrawn in markets, it is still been found to be detected. Out of all the techniques, QTOF-LC/MS detected concentrations of sibutramine adulterated in $9.4 \mathrm{mg}$ and had LOD and LOQ values of $0.4-2.0 \mu \mathrm{g} \mathrm{kg}^{-1}$ and $1.3-6.0 \mu \mathrm{g} \mathrm{kg}^{-1}$ respectively, meaning that it has the ability to detect adulterated Sibutramine even if it was present in $1 \mu \mathrm{g}$ within $1 \mathrm{kilogram}$. LC/MS/MS is also used rather frequently as it is also a highly developed, sensitive technique, but QTOF-LC/MS is the best technique compared to all the other techniques as it has advantages of higher sensitivity, accuracy of mass and high resolution. However, research is currently undergoing to combine spectroscopic techniques other than MS, to overcome disadvantages such as lack of global information, false-positive results, time and labor consumption to detect Sibutramine adulteration in the future.

\section{Reference}

Ancuceanu, R., Dinu, M. \& Arama, C. (2013) Weight loss food supplements: adulteration and multiple quality issues in two products of Chinese origin, Farmacia, 61, 28-44.

Ariburnu, E., Uludag, M. F., Yalcinkaya, H. \& Yesilada, E. (2012) Comparative determination of sibutramine as an adulterant in natural slimming products by HPLC and HPTLC densitometry, Journal of Pharmaceutical and Biomedical Analysis, 64, 77-81.

Bogusz, M. J., Hassan, H., Al-Enazi, E., Ibrahim, Z. \& Al-Tufail, M. (2006) Application of LC-ESI-MS-MS for detection of synthetic adulterants in herbal remedies, Journal of Pharmaceutical and Biomedical Analysis, 41, 554-564.

Calahan, J., Howard, D., Almalki, A. J., Gupta, M. P. \& Calderon, A. I. (2016) Chemical adulterants in herbal medicinal products: a review, Planta Medica, 82, 505-515.

Chauhan, A., Goyal, M. K. \& Chauhan, P. (2014) GC-MS Technique and its Analytical Applications in Science and Technology, Journal of Analytical \& Bioanalytical Techniques, 5.

Chen, Y., Zhao, L., Lu, F., Yu, Y., Chai, Y. \& Wu, Y. (2009) Determination of synthetic drugs used to adulterate botanical dietary supplements using QTRAP LC-MS/MS, Food Additives \& Contaminants: Part A, 26, 595-603.

Creatore, M. I., Glazier, R. H., Moineddin, R., Fazli, G. S., Johns, A., Gozdyra, P., Matheson, F. I., KaufmanShriqui, V., Rosella, L. C., Manuel, D. G. \& Booth, G. L. (2016) Association of neighborhood walkability with change in overweight, obesity, and diabetes, Journal of the American Medical Association, 315, 2211-2220.

Csupor, D., Boros, K., Danko, B., Veres, K., Szendrei, K. \& Hohmann, J. (2013) Rapid identification of sibutramine in dietary supplements using a stepwise approach, Die Pharmazie-An International Journal of Pharmaceutical Sciences, 68, 15-18.

Da lio lu, N. \& Akcan, R. (2012) High dosage sibutramine detected in Chinese herbal drug, Nobel Medicus, 8, 100-102. 
Deconinck, E., Cauwenbergh, T., Bothy, J. L., Custers, D., Courselle, P. \& De Beer, J. O. (2014) Detection of sibutramine in adulterated dietary supplements using attenuated total reflectance-infrared spectroscopy, Journal of Pharmaceutical and Biomedical Analysis, 100, 279-283.

Deconinck, E., Sacre, P. Y., Courselle, P. \& De Beer, J. O. (2013) Chromatography in the detection and characterisation of illegal pharmaceutical preparations, Journal of Chromatographic Science, 51, 791-806.

Florentin, M., Liberopoulos, E. N \& Elisaf, M. S. (2008) Sibutramine-associated adverse effects: a practical guide for its safe use, Obesity Reviews, 9, 378-387.

Haneef, J., Shaharyar, M., Husain, A., Rashid, M., Mishra, R., Siddique, N. A \& Pal, M. (2013) Analytical methods for the detection of undeclared synthetic drugs in traditional herbal medicines as adulterants, Drug Testing and Analysis, 5, 607-613.

Huang, Z., Xiao, S., Luo, D., Chen, B. \& Yao, S. (2008) Simultaneous determination of Sibutramine and N-Didesmethylsibutramine in dietary supplements for weight control by HPLC-ESI-MS, Journal of Chromatographic Science, 46, 707-711.

Johansson, M., Fransson, D., Rundlof, T., Huynh, N. H. \& Arvidsson, T. (2014) A general analytical platform and strategy in search for illegal drugs, Journal of Pharmaceutical and Biomedical Analysis, 100, 215-229.

Jordan, M. A. (2013) Interactions with drugs and dietary supplements used for weight loss, INTECH Open Access Publisher.

Jung, J., Hermanns-Clausen, M. \& Weinmann, W. (2006) Anorectic sibutramine detected in a Chinese herbal drug for weight loss, Forensic Science International, 161, 221-222.

Kamboj, A. (2012) Analytical evaluation of herbal drugs, Drug Discovery Research in Pharmacognosy.

Khazan, M., Hedayati, M., Kobarfard, F., Askari, S. \& Azizi, F. (2014) Identification and determination of synthetic pharmaceuticals as adulterants in eight common herbal weight loss supplements, Iranian Red Crescent Medical Journal, 16.

Li, M., Hou, X. F., Zhang, J., Wang, S. C., Fu, Q. \& He, L. C. (2011) Applications of HPLC/MS in the analysis of traditional Chinese medicines, Journal of Pharmaceutical Analysis, 1, 81-91.

Liang, Q., Qu, J., Luo, G. \& Wang, Y. (2006) Rapid and reliable determination of illegal adulterant in herbal medicines and dietary supplements by LC/MS/MS, Journal of Pharmaceutical and Biomedical Analysis, 40, 305-311.

Lu, F., Li, S., Le, J., Chen, G., Cao, Y., Qi, Y., Chai, Y. \& Wu, Y. (2007) A new method for testing synthetic drugs adulterated in herbal medicines based on infrared spectroscopy, Analytica Chimica Acta, 589, 200-207.

Mathon, C., Ankli, A., Reich, E., Bieri, S. \& Christen, P. (2014) Screening and determination of sibutramine in adulterated herbal slimming supplements by HPTLC-UV densitometry, Food Additives \& Contaminants: Part A, 31, 15-20.

Mendis, S. (2014) Global status report on noncommunicable diseases 2014, at http://apps.who.int/iris/bitstream/10665/148114/1/9789241564854_eng.pdf, World Health Organization, visited 29 October 2016. 
Miller, L. G., Hume, A., Harris, F. I. M., Jackson, E. A., Kanmaz, T. J., Cauffield, J. S., Chin, T.W.F. \& Knell, M. (2001) Adulteration: its various meanings, Pharmacotherapy: The Journal of Human Pharmacology and Drug Therapy, 21, 770-771.

Monakhova, Y. B., Kuballa, T., Lobell-Behrends, S., Maixner, S., Kohl-Himmelseher, M., Ruge, W. \& Lachenmeier, D. W. (2012) Standardless ${ }^{1} \mathrm{H}$ NMR determination of pharmacologically active substances in dietary supplements and medicines that have been illegally traded over the Internet, Drug Testing and Analysis, 5, 400-411.

Nielsen, M. K. K., Johansen, S. S., Dalsgaard, P. W. \& Linnet, K. (2010) Simultaneous screening and quantification of 52 common pharmaceuticals and drugs of abuse in hair using UPLC-TOF-MS, Forensic Science International, 196, 85-92.

Nnaji, C. N., Mach, P. M., Acheampong, J. S., Falconer, T. M. \& Verbeck, G. F. (2016) Analysis of trace amounts of adulterants found in powders/supplements utilizing Raman spectroscopy coupled to direct analyteprobed nanoextraction-nanospray ionization-mass spectrometry, Analytical Methods, 8, 4798-4807.

Oberholzer, H. M., Bester, M. J., Schoor, C. \& Venter, C. (2014) Weight loss products adulterated with sibutramine: a focused review of associated risks, Journal of Endocrinology, Diabetes \& Obesity, 2, 1061.

Phattanawasin, P., Sotanaphun, U., Sukwattanasinit, T., Akkarawaranthorn, J. \& Kitchaiya, S. (2012) Quantitative determination of sibutramine in adulterated herbal slimming formulations by TLC-image analysis method, Forensic Science International, 219, 96-100.

Pitt, J. (2009) Principles and applications of liquid chromatography-mass spectrometry in clinical biochemistry, The Clinical Biochemist Reviews, 30, 19-34.

Raja, S. (2015) A review on determination of adulterants from marketed herbal products by quantitative analytical techniques, Indo American Journal of Pharmaceutical Research, 5, 1432-1446.

Rebiere, H., Guinot, P., Civade, C., Bonnet, P. A. \& Nicolas, A. (2011) Detection of hazardous weight-loss substances in adulterated slimming formulations using ultra-high-pressure liquid chromatography with diodearray detection, Food Additives \& Contaminants: Part A, 29, 161-171.

Rocha, T., Amaral, J. S. \& Oliveira, M. B. P. P. (2015) Adulteration of dietary supplements by the illegal addition of synthetic drugs: a review, Comprehensive Reviews in Food Science and Food Safety, 15, 43-62.

Roh, S. H., Kang, Y. P., Park, S., Huh, Y., Lee, J., Park, J. H., Kim, D. \& Kwon, S. W. (2011) Determination of tadalafil and N-desmethylsibutramine in health and dietary supplements using ultra-performance liquid chromatography (UPLC) coupled with quadrupole-time-of-flight mass spectrometry (Q-TOF MS), Food Additives \& Contaminants: Part A, 28, 1475-1482.

Shi, Y., Sun, C., Gao, B. \& Sun, A. (2011) Development of a liquid chromatography tandem mass spectrometry method for simultaneous determination of eight adulterants in slimming functional foods, Journal of Chromatography A, 1218, 7655-7662.

Siddiqui, M. R., AlOthman, Z. A. \& Rahman, N. (2013) Analytical techniques in pharmaceutical analysis: A review, Arabian Journal of Chemistry.

Sjursnes, B. J., Kvittingen, L. \& Schmid, R. (2014) Normal and reversed-phase thin layer chromatography of green leaf extracts, Journal of Chemical Education, 92, 193-196. 
Skalicka-Wozniak, K., Georgiev, M. I. \& Orhan, I. E. (2016) Adulteration of herbal sexual enhancers and slimmers: the wish for better sexual well-being and perfect body can be risky, Food and Chemical Toxicology.

Vaclavik, L., Krynitsky, A. J. \& Rader, J. I. (2014) Mass spectrometric analysis of pharmaceutical adulterants in products labeled as botanical dietary supplements or herbal remedies: a review, Analytical and Bioanalytical Chemistry, 406, 6767-6790.

Vaysse, J., Balayssac, S., Gilard, V., Desoubdzanne, D., Malet-Martino, M. \& Martino, R. (2010) Analysis of adulterated herbal medicines and dietary supplements marketed for weight loss by DOSY 1H-NMR, Food Additives \& Contaminants: Part A, 27, 903-916.

Vidal, C. \& Quandte, S. (2006) Identification of a sibutramine-metabolite in patient urine after intake of a "pure herbal" Chinese slimming product, Therapeutic Drug Monitoring, 28, 690-692.

Wang, J., Chen, B. \& Yao, S. (2008) Analysis of six synthetic adulterants in herbal weight-reducing dietary supplements by LC electrospray ionization-MS, Food Additives \& Contaminants: Part A, 25, 822-830.

Yano, H. M., Farias, F. F., Del Bianco, M. B. \& Trujillo, L. M. (2013) Determination of the Sibutramine content of dietary supplements using LC-ESI-MS/MS, Latin American Journal of Pharmacy, 32, 1164-1169.

Yu, Z., Wei, Q., Fan, Q. \& Wan, C. (2010) A simple and convenient method for simultaneous determination of four major species of illegal additives in slimming health food, Journal of Liquid Chromatography \& Related Technologies, 33, 452-461.

Yuen, Y. P., Lai, C. K., Poon, W. T., Ng, S. W., Chan, A. Y. \& Mak, T. W. (2007) Adulteration of over-thecounter slimming products with pharmaceutical analogues- an emerging threat, Hong Kong Medical Journal, 13, 216.

Zou, P., Oh, S. S. Y., Kiang, K. H., Low, M. Y. \& Bloodworth, B. C. (2007) Detection of sibutramine, its two metabolites and one analogue in a herbal product for weight loss by liquid chromatography triple quadrupole mass spectrometry and time-of-flight mass spectrometry, Rapid Communications in Mass Spectrometry, 21, 614-61 